\title{
Proteomic and genomic profiling of pancreatic cancer
}

\author{
Daniel Ansari • William Torén • Qimin Zhou • \\ Dingyuan Hu $\cdot$ Roland Andersson
}

Received: 30 October 2018 / Accepted: 5 February 2019 /Published online: 15 February 2019

(C) The Author(s) 2019

\begin{abstract}
Pancreatic cancer remains the most fatal human tumor type. The aggressive tumor biology coupled with the lack of early detection strategies and effective treatment are major reasons for the poor survival rate. Collaborative research efforts have been devoted to understand pancreatic cancer at the molecular level. Large-scale genomic studies have generated important insights into the genetic drivers of pancreatic cancer. In the post-genomic era, protein sequencing of tumor tissue, cell lines, pancreatic juice, and blood from patients with pancreatic cancer has provided a fundament for the development of new diagnostic and prognostic biomarkers. The integration of mass spectrometry and genomic sequencing strategies may help characterize protein identities and post-translational modifications that relate to a specific mutation. Consequently, proteomic and genomic techniques have become a compulsory requirement in modern medicine and health care. These types of proteogenomic studies may usher in a new era
\end{abstract}

D. Ansari $(\bowtie) \cdot$ W. Torén $\cdot$ Q. Zhou $\cdot$ D. Hu $\cdot$ R. Andersson

Department of Surgery, Clinical Sciences Lund, Skåne University Hospital, Lund University, SE-221 85 Lund, Sweden e-mail: daniel.ansari@med.lu.se

Q. Zhou

School of Ophthalmology and Optometry, Eye Hospital, Wenzhou Medical University, Wenzhou, China

D. $\mathrm{Hu}$

Department of Gastroenterology, The Second Affiliated Hospital and Yuying Children's Hospital of Wenzhou Medical University, Wenzhou, China of precision diagnostics and treatment in patients with pancreatic cancer.

Keywords Pancreatic cancer Proteomics · Genomics · Proteogenomics $\cdot$ Biomarkers

\section{Introduction}

Of all major human cancers, pancreatic ductal adenocarcinoma has the most dismal prognosis. Pancreatic ductal adenocarcinoma, henceforth referred to as pancreatic cancer, has risen to become the third leading cause of cancer death in the USA, with a 5-year survival rate of $8 \%$ (Siegel et al., 2018). Without scientific advances and clinical innovations, pancreatic cancer will become the second cancer killer within the coming years, after lung cancer (Rahib et al., 2014). Surgery is the only potentially curative treatment available today. Unfortunately, only about $15-20 \%$ of patients have localized tumors that can be surgically resected (Ansari et al., 2016; Yeo and Cameron, 1999). Recent advances in pancreatic surgery, including centralization to high-volume centers, have increased the resection rates and decreased short-term mortality (Ahola et al., 2017). However, the long-term survival for pancreatic cancer has only minimally improved in the past six decades, when all tumor stages are considered (Ansari et al., 2016).

The diagnosis of pancreatic cancer is often delayed due to lack of early, disease-specific symptoms. Furthermore, there is a deficiency of accurate molecular 
strategies for diagnosis, prognosis, and treatment selection. Carbohydrate antigen 19-9 (CA 19-9) is the only clinical biomarker for pancreatic cancer that is approved by the FDA. Measurement of CA 19-9 in serum can be used for diagnostic workup of pancreatic lesions or for evaluation of treatment response after surgery or chemotherapy (Duffy et al., 2010). However, CA 19-9 is not recommended in a screening setting, due to inadequate sensitivity and specificity.

The progress within proteomic and genomic research has greatly increased our knowledge regarding the molecular basis of pancreatic cancer (Ansari et al., 2014; Bailey et al., 2016). Translating these proteomic and genomic findings into clinical practice is the next phase in order to provide innovations that can improve clinical management. New biomarkers represent an unmet need in pancreatic cancer. Protein or genomic markers detected in body fluids can be used for early diagnosis, prognosis, prediction of treatment response, and development of new targeted treatment. This review highlights the expanding importance of proteomic and genomic research in pancreatic cancer.

\section{CA 19-9}

CA 19-9 is an oligosaccharide that is expressed by mucins. The sensitivity of CA 19-9 for diagnosis of pancreatic cancer is estimated at $79 \%$, with a specificity at $83 \%$ (Poruk et al., 2013). Increased levels of CA 19-9 can be caused by other pancreaticobiliary diseases, such as chronic pancreatitis or biliary obstruction. Approximately $10 \%$ of the population cannot express CA 19-9, due to the lack of the necessary Lewis glycosyltransferase (Goonetilleke and Siriwardena, 2007; Kawai et al., 2008; Kim et al., 2004).

CA 19-9 is often used together with CT and MRI in the diagnostic workup for pancreatic cancer. However, CA 19-9 is not accepted as a screening test for pancreatic cancer (Locker et al., 2006). Increased CA 19-9 levels may indicate disease progression, recurrence and poor outcome in patients with pancreatic cancer (Duffy et al., 2010).

In spite of its limitations, CA 19-9 is still the most widely used tumor marker for pancreatic cancer. Proteomic and genomic studies must therefore use CA 19-9 as a benchmark for which to compare, evaluate, and develop new biomarkers.

\section{Proteomic biomarkers}

Mass spectrometry (MS) is a central technological platform in proteomic research. Biological samples are complex and usually require that the proteome be separated prior to analysis. Separations based on gel chromatography or liquid chromatography are commonly performed. MS analysis of proteins is done either as intact proteins (top-down) or as enzymatically digested protein peptides (bottom-up). Several methods have been developed for protein quantification, such as chemical labeling by isobaric tags for relative and absolute quantitation (iTRAQ) or isotope-coded affinity tag (ICAT), metabolic labeling by SILAC, or label-free techniques. Antibody techniques such as immunohistochemistry and ELISA are also important tools in proteomic research once the target protein has been established.

Tumor-derived proteins detectable in tumor tissue, cell lines, pancreatic juice, and blood have great possibility to be used as tumor biomarkers. Such proteins can hopefully be applied for improving clinical management (Tables 1, 2, 3, and 4).

\section{Tissue}

Pancreatic cancer tissue is the most direct source of tumor-associated proteins. With improvements in proteomic technology, it has become possible to analyze the pancreatic cancer proteome with impressive depth and detail, also describing post-translational modifications.

Detection and characterization of precursor lesions can enable new insights into early diagnosis and timely treatment of pancreatic cancer. Pancreatic intraepithelial neoplasia-3 (PanIN-3) is an established precursor lesion of pancreatic cancer. Quantitative MS analysis using iTRAQ and ICAT was applied to study protein expression in PanIN-3, pancreatic cancer, and control tissues (Pan et al., 2009). The study found multiple aberrantly regulated proteins already in the earliest stages of pancreatic cancer development, as evident by the overlap of proteins in PanIN-3 and pancreatic cancer. Of the aberrantly regulated proteins in PanIN-3 compared to normal pancreas, multiple proteins could be categorized as being involved in cell motility, cell cycle regulation, and inflammation. Immunohistochemistry was conducted on chosen biomarker candidates. Galectin- 1 and laminin beta- 1 were overexpressed in the stroma adjacent to 
Table 1 Selected proteomic biomarkers in tissue

\begin{tabular}{|c|c|c|c|}
\hline Biomarker & Method of detection & Application & Reference \\
\hline Actinin-4 & iTRAQ, ICAT, LC-MS/MS, IHC & Diagnostic & (Pan et al., 2009) \\
\hline Annexin A2 & ICAT, LC-MS/MS & Diagnostic & (Chen et al., 2007a) \\
\hline \multirow[t]{2}{*}{ Bcl-2 } & $\mathrm{IHC}$ & Prognostic & (Nio et al., 2001) \\
\hline & IHC & Prognostic & (Dong et al., 2005) \\
\hline Cathepsin D & ICAT, LC-MS/MS & Diagnostic & (Chen et al., 2007a) \\
\hline \multirow[t]{2}{*}{ CD34 } & $\mathrm{IHC}$ & Prognostic & (Ikeda et al., 1999) \\
\hline & $\mathrm{IHC}$ & Prognostic & (Fujioka et al., 2001) \\
\hline CEACAM5 & LC-MS/MS & Diagnostic & (Pan et al., 2014) \\
\hline \multirow[t]{2}{*}{ COX-2 } & $\mathrm{IHC}$ & Prognostic & (Juuti et al., 2006) \\
\hline & $\mathrm{IHC}$ & Prognostic & (Matsubayashi et al., 2007) \\
\hline Galectin-1 & iTRAQ, ICAT, LC-MS/MS, IHC & Diagnostic & (Pan et al., 2009) \\
\hline $\mathrm{H} 1.3$ & LC-MS/MS & Prognostic & (Bauden et al., 2017) \\
\hline \multirow[t]{3}{*}{ hENT1 } & $\mathrm{IHC}$ & Predictive/prognostic & (Greenhalf et al., 2014) \\
\hline & $\mathrm{IHC}$ & Predictive/prognostic & (Farrell et al., 2009) \\
\hline & $\mathrm{IHC}$ & Predictive/prognostic & (Marechal et al., 2009) \\
\hline IGFBP2 & ICAT, LC-MS/MS & Diagnostic & (Chen et al., 2007a) \\
\hline IGFBP3 & LC-MS/MS & Diagnostic & (Pan et al., 2014) \\
\hline Integrin 1 & ICAT, LC-MS/MS & Diagnostic & (Chen et al., 2007a) \\
\hline \multirow[t]{4}{*}{ Ki-67 } & $\mathrm{IHC}$ & Prognostic & (Linder et al., 1997) \\
\hline & $\mathrm{IHC}$ & Prognostic & (Shyr et al., 1999) \\
\hline & $\mathrm{IHC}$ & Prognostic & (Yamamoto et al., 2004) \\
\hline & $\mathrm{IHC}$ & Prognostic & (Karamitopoulou et al., 2010) \\
\hline Laminin beta 1 & iTRAQ, ICAT, LC-MS/MS, IHC & Diagnostic & (Pan et al., 2009) \\
\hline LGALS3BP & LC-MS/MS & Diagnostic & (Pan et al., 2014) \\
\hline MUC5AC & LC-MS/MS & Diagnostic & (Pan et al., 2014) \\
\hline \multirow[t]{3}{*}{ P27 } & $\mathrm{IHC}$ & Prognostic & (Lu et al., 2000) \\
\hline & $\mathrm{IHC}$ & Prognostic & (Juuti et al., 2003) \\
\hline & $\mathrm{IHC}$ & Prognostic & (Fukumoto et al., 2004) \\
\hline \multirow[t]{2}{*}{ P53 } & $\mathrm{IHC}$ & Prognostic & (Linder et al., 1997) \\
\hline & $\mathrm{IHC}$ & Prognostic & (Ahrendt et al., 2000) \\
\hline Plasminogen & ICAT, LC-MS/MS & Diagnostic & (Chen et al., 2007a) \\
\hline \multirow[t]{2}{*}{ S100A4 } & $\mathrm{IHC}$ & Prognostic & (Ai et al., 2008) \\
\hline & IHC & Prognostic & (Oida et al., 2006) \\
\hline \multirow[t]{2}{*}{ Survivin } & $\mathrm{IHC}$ & Prognostic & (Kami et al., 2004) \\
\hline & $\mathrm{IHC}$ & Prognostic & (Tonini et al., 2005) \\
\hline \multirow[t]{2}{*}{ TGF- $\beta 1$} & $\mathrm{IHC}$ & Prognostic & (Nio et al., 2005) \\
\hline & $\mathrm{IHC}$ & Prognostic & (Hashimoto et al., 2001) \\
\hline \multirow[t]{3}{*}{ VEGF } & $\mathrm{IHC}$ & Prognostic & (Ikeda et al., 1999) \\
\hline & $\mathrm{IHC}$ & Prognostic & (Sun et al., 2007) \\
\hline & $\mathrm{IHC}$ & Prognostic & (Ai et al., 2008) \\
\hline
\end{tabular}

$\overline{I C A T \text { isotope-coded affinity tag, IHC immunohistochemistry, } i T R A Q \text { isobaric tags for relative and absolute quantitation, } L C-M S / M S \text { liquid }}$ chromatography tandem mass spectrometry 
Table 2 Selected proteomic biomarkers in cell lines

\begin{tabular}{|c|c|c|}
\hline Biomarker & Method of detection & Reference \\
\hline ApoE & SILAC, LC-MS/MS, IHC & $\begin{array}{l}\text { (Gronborg et al., } \\
\text { 2006) }\end{array}$ \\
\hline CD9 & SILAC, LC-MS/MS, IHC & $\begin{array}{l}\text { (Gronborg et al., } \\
\text { 2006) }\end{array}$ \\
\hline $\begin{array}{l}\text { Fibronectin } \\
\text { receptor }\end{array}$ & SILAC, LC-MS/MS, IHC & $\begin{array}{l}\text { (Gronborg et al., } \\
\text { 2006) }\end{array}$ \\
\hline Perlecan & SILAC, LC-MS/MS, IHC & $\begin{array}{l}\text { (Gronborg et al., } \\
\text { 2006) }\end{array}$ \\
\hline S100A6 & $\begin{array}{l}\text { Laser capture microdissection, } \\
\text { 2-DE, IHC }\end{array}$ & $\begin{array}{l}\text { (Shekouh et al., } \\
\text { 2003) }\end{array}$ \\
\hline S100A8 & $\begin{array}{l}\text { Laser capture microdissection, } \\
\text { 2-DE }\end{array}$ & $\begin{array}{l}\text { (Sheikh et al., } \\
\text { 2007) }\end{array}$ \\
\hline S100A9 & $\begin{array}{l}\text { Laser capture microdissection, } \\
\text { 2-DE }\end{array}$ & $\begin{array}{l}\text { (Sheikh et al., } \\
\text { 2007) }\end{array}$ \\
\hline SDF4 & SILAC, LC-MS/MS, IHC & $\begin{array}{l}\text { (Gronborg et al., } \\
\text { 2006) }\end{array}$ \\
\hline SMAD4 & $\mathrm{IHC}$ & $\begin{array}{l}\text { (Wang et al., } \\
\text { 2017) }\end{array}$ \\
\hline
\end{tabular}

2-DE two-dimensional gel electrophoresis, IHC immunohistochemistry, $L C-M S / M S$ liquid chromatography tandem mass spectrometry, SILAC stable isotope labeling with amino acids in cell culture

PanIN 3, while actinin-4 was overexpressed in the stroma and ductal epithelium of pancreatic cancer.

Another quantitative proteomic study investigated differences in protein expression between chronic pancreatitis and pancreatic cancer using ICAT (Chen et al., 2007a). Among the aberrantly expressed proteins in chronic pancreatitis, $40 \%$ were also altered in pancreatic cancer. The observations were further confirmed by Western blot and immunohistochemistry. Annexin A2 and IGFBP2 were found to be overexpressed in pancreatic cancer, but not in chronic pancreatitis. Integrin 1 , cathepsin $\mathrm{D}$, and plasminogen were overexpressed in both pancreatic cancer and chronic pancreatitis. The partly, mutual molecular signatures between chronic pancreatitis and pancreatic cancer have also been suggested by another study using label-free quantitative MS (Pan et al., 2011). These similarities in molecular expression indicate that inflammation has a central role in pancreatic cancer pathophysiology.

Post-translational modifications regulate the activity of most proteins. By studying these modifications, we can gain important insights into biological function and also improve biomarker discovery. One study compared the level of $\mathrm{N}$-glycosylation of glycoproteins in pancreatic cancer and normal pancreatic tissue (Pan et al., 2014). Altered N-glycosylation in pancreatic cancer tissue compared to normal pancreatic tissue was reported for MUC5AC, LGALS3BP, CEACAM5, and IGFBP3. Another study displayed the increased level of $\mathrm{N}$-glycosylation of Thy-1 membrane glycoprotein in pancreatic cancer (Foygel et al., 2013). In a previous study, we analyzed histone variants and their related post-translational modifications in patients with pancreatic cancer (Bauden et al., 2017). Using liquid chromatography-tandem mass spectrometry (LC-MS/ MS), we found histone variant H1.3 to be differentially expressed in pancreatic cancer tissue as compared to normal controls. Histone variant H1.3 was found to be an independent marker of poor survival in patients undergoing surgical resection.

Protein markers can also be associated with disease course. In a previous study, we provided a systematic overview of immunohistochemical markers for survival (Ansari et al., 2011). Many independent prognostic markers were found, but only a limited number of markers were validated in an external study, including Ki-67, p27, p53, VEGF, Bcl-2, TGF- $\beta 1$, survivin, COX-2, hENT1, CD34, and S100A4. Further validation steps are necessary before these markers can be used in clinical routine.

Table 3 Selected proteomic biomarkers in pancreatic juice

\begin{tabular}{lll}
\hline Biomarker & Method of detection & Reference \\
\hline A1BG & $\begin{array}{c}\text { DIGE, LC-MS/MS, IHC, } \\
\text { Western blot }\end{array}$ & (Tian et al., 2008) \\
Caldecrin & ICAT, LC-MS/MS & (Chen et al., 2007b) \\
DJ-1 & $\begin{array}{l}\text { DIGE, LC-MS/MS, IHC, } \\
\text { Western blot }\end{array}$ & (Tian et al., 2008) \\
FGB & ICAT, LC-MS/MS & (Chen et al., 2007b) \\
Lithostathine I $\alpha$ & 2-DE, MALDI-TOF-MS & (Zhou et al., 2007) \\
MMP-9 & DIGE, LC-MS/MS, IHC, & (Tian et al., 2008) \\
L1CAM & WCAT, LC-MS/MS & (Chen et al., 2007b) \\
Plasminogen & ICAT, LC-MS/MS & (Chen et al., 2007b) \\
S100A8 & GeLC-MS/MS & (Chen et al., 2014) \\
S100A9 & GeLC-MS/MS & (Chen et al., 2014) \\
\hline
\end{tabular}

2-DE two-dimensional gel electrophoresis, DIGE difference gel electrophoresis, ELISA enzyme-linked immunosorbent assay, GeLC-MS/MS gel-enhanced liquid chromatography tandem mass spectrometry, ICAT isotope-coded affinity tag, IHC immunohistochemistry, $L C-M S / M S$ liquid chromatography tandem mass spectrometry, MALDI-TOF-MS matrix assisted laser desorption ionization-time of flight mass spectrometry 
Table 4 Selected proteomic biomarkers in serum/plasma

\begin{tabular}{|c|c|c|c|c|}
\hline Biomarker & Method of detection & $\begin{array}{l}\text { Sensitivity } \\
(\%)\end{array}$ & $\begin{array}{l}\text { Specificity } \\
(\%)\end{array}$ & Reference \\
\hline CA 19-9 & ELISA & 78 & 83 & (Poruk et al., 2013) \\
\hline DKK1 & ELISA & 89 & 79 & (Han et al., 2015) \\
\hline Exosomal glypican-1 & UPLC-MS & 100 & 100 & (Melo et al., 2015) \\
\hline HSP-27 & SELDI, ELISA & 100 & 84 & (Melle et al., 2007) \\
\hline IL-11 & ELISA & 98 & 70 & (Ren et al., 2014) \\
\hline MIC-1 & ELISA & 66 & 96 & (Wang et al., 2014) \\
\hline Xylitol + 1,5-anhydro-D-glucitol + histidine + inositol & GC/MS & $71-86$ & $78-88$ & $\begin{array}{l}\text { (Kobayashi et al., } \\
\text { 2013) }\end{array}$ \\
\hline CA 19-9 + MUC5AC & ELISA & 75 & 83 & (Kaur et al., 2017) \\
\hline CA $19-9+$ CA 242 & ELISA & 89 & 75 & $\begin{array}{l}\text { (Zhang et al., } \\
\text { 2015) }\end{array}$ \\
\hline CA 19-9 + IGF-1 + albumin & ELISA & 94 & 95 & (Ferri et al., 2016) \\
\hline CA $19-9$ + CEA + CA 125 + CA 242 & ELISA & 90 & 94 & (Gu et al., 2015) \\
\hline $\mathrm{CA} 19-9+5 \mathrm{MC}+\mathrm{H} 2 \mathrm{AZ}+\mathrm{H} 2 \mathrm{~A} 1.1+\mathrm{H} 3 \mathrm{~K} 4 \mathrm{Me} 2$ & ELISA & 92 & 90 & $\begin{array}{l}\text { (Bauden et al., } \\
\text { 2015) }\end{array}$ \\
\hline $\mathrm{CA} 19-9+\mathrm{CEA}+\mathrm{HGF}+\mathrm{OPN}+\mathrm{ctDNA}$ & $\begin{array}{l}\text { Luminex bead-based } \\
\text { immunoassay, PCR }\end{array}$ & 64 & 99.5 & $\begin{array}{l}\text { (Cohen et al., } \\
\text { 2017) }\end{array}$ \\
\hline CA $19-9+$ THBS2 & ELISA & 87 & 98 & (Kim et al., 2017) \\
\hline 29-Biomarker panel & Antibody microarray & 94 & 95 & $\begin{array}{l}\text { (Mellby et al., } \\
\text { 2018) }\end{array}$ \\
\hline
\end{tabular}

ELISA enzyme-linked immunosorbent assay, GC/MS gas chromatography/mass spectrometry, PCR polymerase chain reaction, SELDI surface-enhanced laser desorption/ionization, $U P L C-M S$ ultra performance liquid chromatography mass spectrometry

\section{Cell lines}

Cell lines are a useful source of biomarkers, as they are easily accessible and enable proteomic analysis of secreted proteins. However, data interpretation is challenging as isolated cells may not be fully representative of patient tumors (Tonack et al., 2009). Several biomarkers have been derived from proteomic research in cell lines.

The secretome of pancreatic cancer cells has been analyzed using SILAC MS profiling (Gronborg et al., 2006). Multiple novel pancreatic cancer biomarkers were identified, including SDF4, perlecan, CD9, the fibronectin receptor and apoE. The proteins were additionally validated with Western blot and immunohistochemistry. Another study identified S100A6 as a pancreatic cancer biomarker in cell lines, using laser capture microdissection, two-dimensional gel electrophoresis (2-DE), MS, and immunohistochemistry (Shekouh et al., 2003).
Cell lines have also been used to study biomarkers for metastatic disease. Primary and metastatic cell lines of pancreatic cancer were analyzed by SDS-PAGE, ingel tryptic digestion and LC-MS/MS. Only about half of identified proteins could be found in both cell types, indicating a remarkably different protein profile. Among the differentially expressed proteins were collagens, integrins, galectins, and cadherins that are functionally related to cell motility and adhesion (Liu et al., 2010). Another study compared cells from primary tumors and lymph node metastasis with laser capture microdissection in combination with LC-MS/MS. S100P and 14-33 sigma were validated as markers of lymphatic engagement using immunohistochemistry (Naidoo et al., 2012). These findings are clinically important, as metastasis is the most important cause of death in pancreatic cancer patients.

The stromal compartment is a major determinant in the biology of pancreatic cancer. Pancreatic stromal cells have been evaluated using laser capture microdissection 


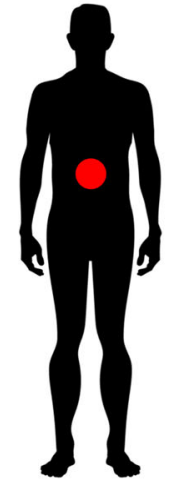

\section{Pancreatic Cancer Patient}

\section{Parallel Sequencing}
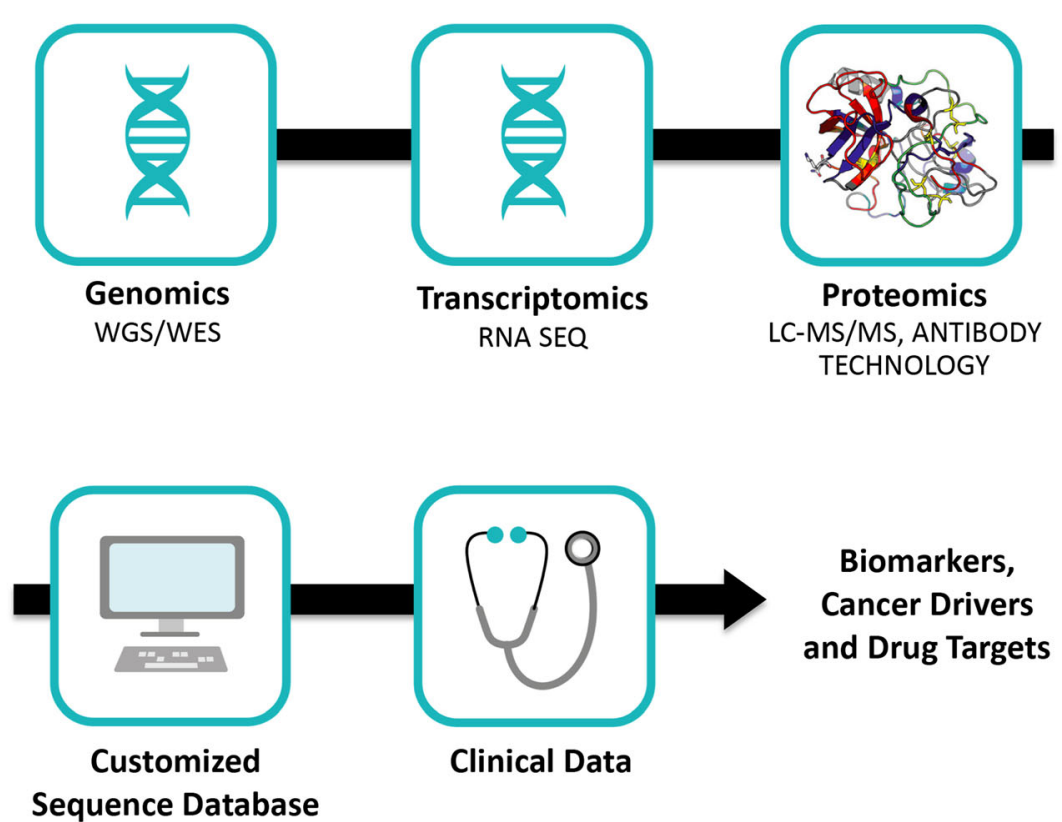

Fig. 1 Development strategy for proteogenomic biomarker in pancreatic cancer. LC-MS/MS liquid chromatography tandem mass spectrometry, WES whole-exosome sequencing, WGS whole-genome sequencing

in combination with 2-DE (Sheikh et al., 2007). S100A8 and S100A9 were found to be overexpressed in the tumor stroma and were also correlated to SMAD4 expression. Protein expression was primarily present on immune cells in the stroma.

\section{Pancreatic juice}

Pancreatic juice is protein-rich and directly secreted from pancreatic ductal cells, making it a valuable source for proteomic studies. Samples can be collected from the pancreatic duct with endoscopic techniques such as ERCP (Tryliskyy and Bryce, 2018). Thus, pancreatic juice has an exceptional composition for proteomic studies but is less available than blood due to the invasive procedure to procure the samples.

Proteomic technologies have been applied to pancreatic juice to develop new biomarkers. Pancreatic juice from patients with pancreatic cancer, benign pancreatic disease, and gallstone disease was analyzed with 2-DE and MALDI-TOF-MS (Zhou et al., 2007). The study found that gallstone disease affects the protein composition of the pancreatic juice. Five proteins were found to be have decreased expression in pancreatic cancer, including lithostathine I $\alpha$. Quantitative proteomic approaches have also been studied in the identification of biomarkers from pancreatic juice in the differentiation between pancreatic cancer and pancreatitis using ICAT and LC-MS/MS (Chen et al., 2007b). Plasminogen, fibrinogen $\beta$-chain, caldecrin, and neural cell adhesion molecule L1 were found to be upregulated. Another study used gel electrophoresis and LC-MS/MS (Tian et al., 2008). DJ-1, MMP-9, and A1BG were found to be upregulated in pancreatic juice and were further investigated by Western blot and immunohistochemistry.

Other mass spectrometric studies of pancreatic juice have found CEA, S100A6, S100A8, S100A9, and S100P to be differentially regulated between pancreatic cancer and benign conditions (Chen et al., 2014; Mori et al., 2013; Ohuchida et al., 2005).

\section{Serum}

The use of a simple blood test to detect pancreatic cancer is an attractive strategy to improve early detection. Thus, much effort has been focused on the identification of serum markers for pancreatic cancer (Han et al., 2015; Melle et al., 2007; Ren et al., 2014). The identification of new biomarkers is, however, complicated by the low concentrations of biomarker candidates in blood and the 
presence of transport proteins, such as albumin, in high concentrations.

Metabolic disorders such as obesity and diabetes mellitus type II are known risk factors for pancreatic cancer. The pathophysiological mechanisms are not well recognized. It is speculated that several proteins associated with obesity and diabetes may also promote pancreatic tumor progression, such as adiponectin, leptin, glucose metabolic enzymes, MMP9, and VNN1 (Pothuraju et al., 2018). Furthermore, proteomic analyses based on MS have reported metabolites and metabolic enzymes as candidate blood biomarkers for diagnosis of pancreatic cancer. The markers histidine, inositol, xylitol, and 1,5-anhydro-D-glucitol were found to be outperform CA 19-9 in the diagnosis of pancreatic cancer from controls (Kobayashi et al., 2013).

Many studies have investigated the combinatory precision of CA 19-9 and various other biomarkers, in order to improve the diagnostic accuracy. For example, CA 199 coupled with MUC5AC provided a sensitivity of $75 \%$ and a specificity of $83 \%$ (Kaur et al., 2017). A metaanalysis reported that the sensitivity of CA 19-9 was increased to $89 \%$ when used together with CA 242 (Zhang et al., 2015). Another study found that a panel of serum CA 19-9, CA 125, CA 242, and CEA had a sensitivity and specificity of $90 \%$ and $94 \%$ (Gu et al., 2015). When using CA 19-9 as a diagnostic marker in combination with albumin and IGF-1, a sensitivity of $94 \%$ and a specificity of $95 \%$ were achieved (Ferri et al., 2016).

In a previous study, we used a novel immunoassay to profile circulating nucleosomes in patients with pancreatic cancer and controls (Bauden et al., 2015). A fivemarker nucleosomes panel was found to be better than CA 19-9 in separating pancreatic cancer sera from healthy control sera, including $\mathrm{H} 3 \mathrm{~K} 4 \mathrm{Me} 2, \mathrm{H} 2 \mathrm{AZ}$, 5MC, H2A1.1, and H2AK119Ub. The four nucleosomes H3K4Me2, H2AZ, 5MC, and H2A1.1 together with CA 19-9 yielded an AUC of 0.98, at a sensitivity of 92\% with $90 \%$ specificity.

Recently, it was reported that CA 19-9 together with THBS2 may enhance the diagnosis of early-stage pancreatic cancer, when validated in large and independent patient groups (Kim et al., 2017). The CA 19-9 and THBS2 panel yielded a sensitivity of $87 \%$ with a specificity of $98 \%$.

Antibody array technology has been applied to develop serum biomarker signatures for diagnosis of pancreatic cancer (Wingren et al., 2012). In a follow-up study, the serum panel was refined to include 29 proteins, which gave an AUC of 0.96 for stage I and II pancreatic cancers, with a sensitivity of $94 \%$ and a specificity of $95 \%$ (Mellby et al., 2018).

Most impressively, however, is the study by Melo et al. that reported an absolute prediction of pancreatic cancer $(\mathrm{AUC}=1.0)$ using glypican-1 on exosomes as identified by MS (Melo et al., 2015). This work has spawned additional interest in the application of exosomes as biomarkers for pancreatic cancer. Carmicheal et al. utilized surface enhanced Raman spectroscopy (SERS) to analyze exosomes derived from pancreatic cancer and normal pancreas cell lines (Carmicheal et al., 2018). A high diagnostic accuracy (90\%) was reported for the exosome-based signature in serum.

\section{Genomic biomarkers}

The genetic alterations in pancreatic cancer have been mapped through large-scale genomic studies. Around 60 altered genes in 12 core pathways have been reported for pancreatic cancer (Bailey et al., 2016; Jones et al., 2008). The KRAS oncogene and CDKN2A have been found to be mutated in more than $90 \%$ of pancreatic cancers, while the TP53 and SMAD4 genes are mutated in $75 \%$ and $55 \%$ of the patients, respectively. The PALB2, BRCA1, and BRCA2 genes have been associated with chemotherapy response in a subcategory of pancreatic cancers (Waddell et al., 2015). Altered DNA methylation in mucin genes, including MUC1 and MUC4, is associated with survival in patients with pancreatic cancer (Yokoyama et al., 2016). Klein et al. reported the findings of the largest whole-genome sequencing data analysis of pancreatic cancer to date (Klein et al., 2018). The study included a metaanalysis of 9040 patients and 12,496 controls and found new susceptibility loci for pancreatic cancer. These loci included TNS3, NOC2L, HNF4G, HNF1B, and GRP.

Pancreatic cancer is a complex and heterogeneous disease. Molecular stratification may provide a roadmap for directing treatment and inform on prognosis. Several genomic subclassifications of pancreatic cancer have been put forth. Subclassification based on biological factors suggests three subtypes of pancreatic cancer, including classical, exocrine-like and quasimesenchymal (Collisson et al., 2011). Importantly, tumor subtype correlated with chemotherapy response and clinical outcome. The stroma of pancreatic cancer has also been suggested as a basis for classification. A "basal-like" 
subtype of stroma was identified and associated with shorter survival. "Normal" and "activated" stroma subtypes were also correlated with clinical outcomes (Moffitt et al., 2015). Bailey et al. suggested four subtypes according to the molecular profile of the tumor, divided into squamous, pancreatic progenitor, and immunogenic, as well as the aberrantly differentiated endocrine-exocrine form (Bailey et al., 2016). However, none of these genomic subclassifications have reached clinical translation and further validation studies are warranted.

\section{Proteogenomic biomarkers}

A multidimensional approach based on the integration of proteomic and genomic technology ultimately leads to a better understanding of pancreatic cancer biology and the development of novel types of biomarkers (Fig. 1).

A biomarker strategy combining proteomic and genomic biomarkers was recently reported (Cohen et al., 2017). The study combined CA 19-9, protein biomarkers (OPN, CEA, HGF), and gene mutations (KRAS). A specificity of $99.5 \%$ was achieved for diagnosis of pancreatic cancer using plasma samples from patients with pancreatic cancer and healthy controls.

Proteogenomic databases such as PGTools have been developed to integrate proteogenomic data (Nagaraj et al., 2015). Using PGTools, more than 200 new protein coding regions in pancreatic cancer exons were discovered that had previously not been reported by single genetic or proteomic methods. Methods such as PGTools may help to generate peptide sequences from RNA transcripts, classify proteins, identify dysregulated proteins, and report false discovery rates (available at https://omictools.com/pgtools-tool).

\section{Conclusion}

CA 19-9 remains the only approved biomarker for pancreatic cancer by FDA standards, despite extensive research into new markers. This can partially be explained by the extensive validation process necessary to translate biomarker findings into the clinic, including the need for large-scale, multicenter trials that are costly and time consuming. Another challenge is the lack of bioanalytical techniques yielding precise, reproducible analyses of clinical samples with cost-effectiveness for the society at large. However, with the rapidly improving accuracy and throughput of proteomic and genomic analytic instruments, there is a great prospect that proteomic and genomic technologies could be applied in everyday health care.

Open Access This article is distributed under the terms of the Creative Commons Attribution 4.0 International License (http:// creativecommons.org/licenses/by/4.0/), which permits unrestricted use, distribution, and reproduction in any medium, provided you give appropriate credit to the original author(s) and the source, provide a link to the Creative Commons license, and indicate if changes were made.

Publisher's note Springer Nature remains neutral with regard to jurisdictional claims in published maps and institutional affiliations.

\section{References}

Ahola R, Siiki A, Vasama K, Vornanen M, Sand J, Laukkarinen J. Effect of centralization on long-term survival after resection of pancreatic ductal adenocarcinoma. Br J Surg. 2017;104: 1532-8.

Ahrendt SA, Brown HM, Komorowski RA, Zhu Y-R, Wilson SD, Erickson BA, et al. p21WAF1 expression is associated with improved survival after adjuvant chemoradiation for pancreatic cancer. Surgery. 2000;128:520-30.

Ai KX, Lu LY, Huang XY, Chen W, Zhang HZ. Prognostic significance of S100A4 and vascular endothelial growth factor expression in pancreatic cancer. World J Gastroenterol. 2008;14:1931-5.

Ansari D, Aronsson L, Sasor A, Welinder C, Rezeli M, MarkoVarga G, et al. The role of quantitative mass spectrometry in the discovery of pancreatic cancer biomarkers for translational science. J Transl Med. 2014;12:87.

Ansari D, Rosendahl A, Elebro J, Andersson R. Systematic review of immunohistochemical biomarkers to identify prognostic subgroups of patients with pancreatic cancer. Br J Surg. 2011;98:1041-55.

Ansari D, Tingstedt B, Andersson B, Holmquist F, Sturesson C, Williamsson C, et al. Pancreatic cancer: yesterday, today and tomorrow. Future Oncol. 2016;12:1929-46.

Bailey P, Chang DK, Nones K, Johns AL, Patch AM, Gingras $\mathrm{MC}$, et al. Genomic analyses identify molecular subtypes of pancreatic cancer. Nature. 2016;531:47-52.

Bauden M, Kristl T, Sasor A, Andersson B, Marko-Varga G, Andersson R, et al. Histone profiling reveals the H1.3 histone variant as a prognostic biomarker for pancreatic ductal adenocarcinoma. BMC Cancer. 2017;17:810.

Bauden M, Pamart D, Ansari D, Herzog M, Eccleston M, Micallef $\mathrm{J}$, et al. Circulating nucleosomes as epigenetic biomarkers in pancreatic cancer. Clin Epigenetics. 2015;7:106.

Carmicheal J, Hayashi C, Huang X, Liu L, Lu Y, Krasnoslobodtsev A, et al. Label-free characterization of exosome via surface enhanced Raman spectroscopy for the 
early detection of pancreatic cancer. Nanomedicine. 2018;16: 88-96.

Chen KT, Kim PD, Jones KA, Devarajan K, Patel BB, Hoffman JP, et al. Potential prognostic biomarkers of pancreatic cancer. Pancreas. 2014;43:22-7.

Chen R, Brentnall TA, Pan S, Cooke K, Moyes KW, Lane Z, et al. Quantitative proteomics analysis reveals that proteins differentially expressed in chronic pancreatitis are also frequently involved in pancreatic cancer. Mol Cell Proteomics. 2007a;6: 1331-42.

Chen R, Pan S, Cooke K, Moyes KW, Bronner MP, Goodlett DR, et al. Comparison of pancreas juice proteins from cancer versus pancreatitis using quantitative proteomic analysis. Pancreas. 2007b;34:70-9.

Cohen JD, Javed AA, Thoburn C, Wong F, Tie J, Gibbs P, et al. Combined circulating tumor DNA and protein biomarkerbased liquid biopsy for the earlier detection of pancreatic cancers. Proc Natl Acad Sci U S A. 2017;114:10202-7.

Collisson EA, Sadanandam A, Olson P, Gibb WJ, Truitt M, Gu S, et al. Subtypes of pancreatic ductal adenocarcinoma and their differing responses to therapy. Nat Med. 2011;17:500-3.

Dong M, Zhou JP, Zhang H, Guo KJ, Tian YL, Dong YT. Clinicopathological significance of Bcl-2 and Bax protein expression in human pancreatic cancer. World J Gastroenterol. 2005;11:2744-7.

Duffy MJ, Sturgeon C, Lamerz R, Haglund C, Holubec VL, Klapdor R, et al. Tumor markers in pancreatic cancer: a European Group on Tumor Markers (EGTM) status report. Ann Oncol. 2010;21:441-7.

Farrell JJ, Elsaleh H, Garcia M, Lai R, Ammar A, Regine WF, et al. Human equilibrative nucleoside transporter 1 levels predict response to gemcitabine in patients with pancreatic cancer. Gastroenterology. 2009;136:187-95.

Ferri MJ, Saez M, Figueras J, Fort E, Sabat M, Lopez-Ben S, et al. Improved pancreatic adenocarcinoma diagnosis in jaundiced and non-jaundiced pancreatic adenocarcinoma patients through the combination of routine clinical markers associated to pancreatic adenocarcinoma pathophysiology. PLoS One. 2016;11:e0147214.

Foygel K, Wang H, Machtaler S, Lutz AM, Chen R, Pysz M, et al. Detection of pancreatic ductal adenocarcinoma in mice by ultrasound imaging of thymocyte differentiation antigen 1 . Gastroenterology. 2013;145:885-894.e883.

Fujioka S, Yoshida K, Yanagisawa S, Kawakami M, Aoki T, Yamazaki Y. Angiogenesis in pancreatic carcinoma: thymidine phosphorylase expression in stromal cells and intratumoral microvessel density as independent predictors of overall and relapse-free survival. Cancer. 2001;92:178897.

Fukumoto A, Ikeda N, Sho M, Tomoda K, Kanehiro H, Hisanaga $\mathrm{M}$, et al. Prognostic significance of localized p27Kip1 and potential role of Jab1/CSN5 in pancreatic cancer. Oncol Rep. 2004;11:277-84.

Goonetilleke KS, Siriwardena AK. Systematic review of carbohydrate antigen (CA 19-9) as a biochemical marker in the diagnosis of pancreatic cancer. Eur J Surg Oncol. 2007;33: 266-70.

Greenhalf W, Ghaneh P, Neoptolemos JP, Palmer DH, Cox TF, Lamb RF, et al. Pancreatic cancer hENT1 expression and survival from gemcitabine in patients from the ESPAC-3 trial. J Natl Cancer Inst. 2014;106:djt347.
Gronborg M, Kristiansen TZ, Iwahori A, Chang R, Reddy R, Sato $\mathrm{N}$, et al. Biomarker discovery from pancreatic cancer secretome using a differential proteomic approach. Mol Cell Proteomics. 2006;5:157-71.

Gu YL, Lan C, Pei H, Yang SN, Liu YF, Xiao LL. Applicative value of serum CA19-9, CEA, CA125 and CA242 in diagnosis and prognosis for patients with pancreatic cancer treated by concurrent chemoradiotherapy. Asian Pac J Cancer Prev. 2015;16:6569-73.

Han SX, Zhou X, Sui X, He CC, Cai MJ, Ma JL, et al. Serum dickkopf-1 is a novel serological biomarker for the diagnosis and prognosis of pancreatic cancer. Oncotarget. 2015;6: 19907-17.

Hashimoto K, Nio Y, Sumi S, Toga T, Omori H, Itakura M, et al. Correlation between TGF-beta1 and p21 (WAF1/CIP1) expression and prognosis in resectable invasive ductal carcinoma of the pancreas. Pancreas. 2001;22:341-7.

Ikeda N, Adachi M, Taki T, Huang C, Hashida H, Takabayashi A, et al. Prognostic significance of angiogenesis in human pancreatic cancer. Br J Cancer. 1999;79:1553-63.

Jones S, Zhang X, Parsons DW, Lin JC, Leary RJ, Angenendt P, et al. Core signaling pathways in human pancreatic cancers revealed by global genomic analyses. Science. 2008;321: 1801-6.

Juuti A, Louhimo J, Nordling S, Ristimäki A, Haglund C. Cyclooxygenase- 2 expression correlates with poor prognosis in pancreatic cancer. J Clin Pathol. 2006;59:382-6.

Juuti A, Nordling S, Louhimo J, Lundin J, von Boguslawski K, Haglund C. Loss of p27 expression is associated with poor prognosis in stage I-II pancreatic cancer. Oncology. 2003;65: 371-7.

Kami K, Doi R, Koizumi M, Toyoda E, Mori T, Ito D, et al. Survivin expression is a prognostic marker in pancreatic cancer patients. Surgery. 2004;136:443-8.

Karamitopoulou E, Zlobec I, Tornillo L, Carafa V, Schaffner T, Brunner T, et al. Differential cell cycle and proliferation marker expression in ductal pancreatic adenocarcinoma and pancreatic intraepithelial neoplasia (PanIN). Pathology. 2010;42:229-34.

Kaur S, Smith LM, Patel A, Menning M, Watley DC, Malik SS, et al. A combination of MUC5AC and CA19-9 improves the diagnosis of pancreatic cancer: a multicenter study. Am J Gastroenterol. 2017;112:172-83.

Kawai S, Suzuki K, Nishio K, Ishida Y, Okada R, Goto Y, et al. Smoking and serum CA19-9 levels according to Lewis and secretor genotypes. Int J Cancer. 2008;123:2880-4.

Kim J, Bamlet WR, Oberg AL, Chaffee KG, Donahue G, Cao XJ, et al. Detection of early pancreatic ductal adenocarcinoma with thrombospondin-2 and CA19-9 blood markers. Sci Transl Med. 2017;9:eaah5583.

Kim JE, Lee KT, Lee JK, Paik SW, Rhee JC, Choi KW. Clinical usefulness of carbohydrate antigen 19-9 as a screening test for pancreatic cancer in an asymptomatic population. $\mathrm{J}$ Gastroenterol Hepatol. 2004;19:182-6.

Klein AP, Wolpin BM, Risch HA, Stolzenberg-Solomon RZ, Mocci E, Zhang M, et al. Genome-wide meta-analysis identifies five new susceptibility loci for pancreatic cancer. Nat Commun. 2018;9:556.

Kobayashi T, Nishiumi S, Ikeda A, Yoshie T, Sakai A, Matsubara A, et al. A novel serum metabolomics-based diagnostic 
approach to pancreatic cancer. Cancer Epidemiol Biomark Prev. 2013;22:571-9.

Linder S, Parrado C, Falkmer UG, Blåsjö M, Sundelin P, von Rosen A. Prognostic significance of Ki-67 antigen and p53 protein expression in pancreatic duct carcinoma: a study of the monoclonal antibodies MIB-1 and DO-7 in formalinfixed paraffin-embedded tumour material. Br J Cancer. 1997;76:54-9.

Liu X, Zhang M, Go VL, Hu S. Membrane proteomic analysis of pancreatic cancer cells. J Biomed Sci. 2010;17:74.

Locker GY, Hamilton S, Harris J, Jessup JM, Kemeny N, Macdonald JS, et al. ASCO 2006 update of recommendations for the use of tumor markers in gastrointestinal cancer. J Clin Oncol. 2006;24:5313-27.

Lu C-D, Morita S, Ishibashi T, Hara H, Isozaki H, Tanigawa N. Loss of p27Kip1 expression independently predicts poor prognosis for patients with resectable pancreatic adenocarcinoma. Cancer. 2000;85:1250-60.

Marechal R, Mackey JR, Lai R, Demetter P, Peeters M, Polus M, et al. Human equilibrative nucleoside transporter 1 and human concentrative nucleoside transporter 3 predict survival after adjuvant gemcitabine therapy in resected pancreatic adenocarcinoma. Clin Cancer Res. 2009;15:2913-9.

Matsubayashi H, Infante JR, Winter JM, Klein AP, Schulick R, Hruban R, et al. Tumor COX-2 expression and prognosis of patients with resectable pancreatic cancer. Cancer Biol Ther. 2007;6:1569-75.

Mellby, L.D., Nyberg, A.P., Johansen, J.S., Wingren, C., Nordestgaard, B.G., Bojesen, S.E., Mitchell, B.L., Sheppard, B.C., Sears, R.C., and Borrebaeck, C.A.K.. Serum biomarker signature-based liquid biopsy for diagnosis of early-stage pancreatic cancer. J Clin Oncol. (2018); JCO2017776658

Melle C, Ernst G, Escher N, Hartmann D, Schimmel B, Bleul A, et al. Protein profiling of microdissected pancreas carcinoma and identification of HSP27 as a potential serum marker. Clin Chem. 2007;53:629-35.

Melo SA, Luecke LB, Kahlert C, Fernandez AF, Gammon ST, Kaye J, et al. Glypican-1 identifies cancer exosomes and detects early pancreatic cancer. Nature. 2015;523:177-82.

Moffitt RA, Marayati R, Flate EL, Volmar KE, Loeza SG, Hoadley KA, et al. Virtual microdissection identifies distinct tumor- and stroma-specific subtypes of pancreatic ductal adenocarcinoma. Nat Genet. 2015;47:1168-78.

Mori Y, Ohtsuka T, Kono H, Nagayoshi Y, Ideno N, Aso T, et al. A minimally invasive and simple screening test for detection of pancreatic ductal adenocarcinoma using biomarkers in duodenal juice. Pancreas. 2013;42:187-92.

Nagaraj SH, Waddell N, Madugundu AK, Wood S, Jones A, Mandyam RA, et al. PGTools: a software suite for proteogenomic data analysis and visualization. J Proteome Res. 2015;14:2255-66.

Naidoo K, Jones R, Dmitrovic B, Wijesuriya N, Kocher H, Hart IR, et al. Proteome of formalin-fixed paraffin-embedded pancreatic ductal adenocarcinoma and lymph node metastases. J Pathol. 2012;226:756-63.

Nio Y, Dong M, Iguchi C, Yamasawa K, Toga T, Itakura M, et al. Expression of $\mathrm{Bcl}-2$ and $\mathrm{p} 53$ protein in resectable invasive ductal carcinoma of the pancreas: effects on clinical outcome and efficacy of adjuvant chemotherapy. J Surg Oncol. 2001;76:188-96.
Nio Y, Omori H, Hashimoto K, Itakura M, Koike M, Yano S, et al. Immunohistochemical expression of receptor-tyrosine kinase c-kit protein and TGF-beta1 in invasive ductal carcinoma of the pancreas. Anticancer Res. 2005;25:3523-9.

Ohuchida K, Mizumoto K, Ishikawa N, Fujii K, Konomi H, Nagai $\mathrm{E}$, et al. The role of S100A6 in pancreatic cancer development and its clinical implication as a diagnostic marker and therapeutic target. Clin Cancer Res. 2005;11:7785-93.

Oida Y, Yamazaki H, Tobita K, Mukai M, Ohtani Y, Miyazaki N, et al. Increased S100A4 expression combined with decreased E-cadherin expression predicts a poor outcome of patients with pancreatic cancer. Oncol Rep. 2006;16:457-63.

Pan S, Chen R, Reimel BA, Crispin DA, Mirzaei H, Cooke K, et al. Quantitative proteomics investigation of pancreatic intraepithelial neoplasia. Electrophoresis. 2009;30:1132-44.

Pan S, Chen R, Stevens T, Bronner MP, May D, Tamura Y, et al. Proteomics portrait of archival lesions of chronic pancreatitis. PLoS One. 2011;6:e27574.

Pan S, Chen R, Tamura Y, Crispin DA, Lai LA, May DH, et al. Quantitative glycoproteomics analysis reveals changes in Nglycosylation level associated with pancreatic ductal adenocarcinoma. J Proteome Res. 2014;13:1293-306.

Poruk KE, Gay DZ, Brown K, Mulvihill JD, Boucher KM, Scaife CL, et al. The clinical utility of CA 19-9 in pancreatic adenocarcinoma: diagnostic and prognostic updates. Curr Mol Med. 2013;13:340-51.

Pothuraju R, Rachagani S, Junker WM, Chaudhary S, Saraswathi V, Kaur S, et al. Pancreatic cancer associated with obesity and diabetes: an alternative approach for its targeting. J Exp Clin Cancer Res. 2018;37:319.

Rahib L, Smith BD, Aizenberg R, Rosenzweig AB, Fleshman JM, Matrisian LM. Projecting cancer incidence and deaths to 2030: the unexpected burden of thyroid, liver, and pancreas cancers in the United States. Cancer Res. 2014;74:2913-21.

Ren C, Chen Y, Han C, Fu D, Chen H. Plasma interleukin-11 (IL11) levels have diagnostic and prognostic roles in patients with pancreatic cancer. Tumour Biol. 2014;35:11467-72.

Sheikh AA, Vimalachandran D, Thompson CC, Jenkins RE, Nedjadi T, Shekouh A, et al. The expression of S100A8 in pancreatic cancer-associated monocytes is associated with the Smad4 status of pancreatic cancer cells. Proteomics. 2007;7:1929-40.

Shekouh AR, Thompson CC, Prime W, Campbell F, Hamlett J, Herrington CS, et al. Application of laser capture microdissection combined with two-dimensional electrophoresis for the discovery of differentially regulated proteins in pancreatic ductal adenocarcinoma. Proteomics. 2003;3:1988-2001.

Shyr YM, Su CH, Li AF, Wu CW, Lui WY. The role of MIB-1 index in the prognosis of resectable pancreatic head cancer. Hepatogastroenterology. 1999;46:2968-73.

Siegel RL, Miller KD, Jemal A. Cancer statistics, 2018. CA Cancer J Clin. 2018;68:7-30.

Sun HC, Qiu ZJ, Liu J, Sun J, Jiang T, Huang KJ, et al. Expression of hypoxia-inducible factor- 1 alpha and associated proteins in pancreatic ductal adenocarcinoma and their impact on prognosis. Int J Oncol. 2007;30:1359-67.

Tian M, Cui YZ, Song GH, Zong MJ, Zhou XY, Chen Y, et al. Proteomic analysis identifies MMP-9, DJ-1 and A1BG as overexpressed proteins in pancreatic juice from pancreatic ductal adenocarcinoma patients. BMC Cancer. 2008;8:241. 
Tonack S, Aspinall-O'Dea M, Neoptolemos JP, Costello E. Pancreatic cancer: proteomic approaches to a challenging disease. Pancreatology. 2009;9:567-76.

Tonini G, Vincenzi B, Santini D, Scarpa S, Vasaturo T, Malacrino C, et al. Nuclear and cytoplasmic expression of survivin in 67 surgically resected pancreatic cancer patients. Br J Cancer. 2005;92:2225-32.

Tryliskyy Y, Bryce GJ. Post-ERCP pancreatitis: pathophysiology, early identification and risk stratification. Adv Clin Exp Med. 2018;27:149-54.

Waddell N, Pajic M, Patch AM, Chang DK, Kassahn KS, Bailey P, et al. Whole genomes redefine the mutational landscape of pancreatic cancer. Nature. 2015;518:495-501.

Wang JD, Jin K, Chen XY, Lv JQ, Ji KW. Clinicopathological significance of SMAD4 loss in pancreatic ductal adenocarcinomas: a systematic review and meta-analysis. Oncotarget. 2017;8:16704-11.

Wang X, Li Y, Tian H, Qi J, Li M, Fu C, et al. Macrophage inhibitory cytokine 1 (MIC-1/GDF15) as a novel diagnostic serum biomarker in pancreatic ductal adenocarcinoma. BMC Cancer. 2014;14:578.
Wingren C, Sandstrom A, Segersvard R, Carlsson A, Andersson $\mathrm{R}$, Lohr M, et al. Identification of serum biomarker signatures associated with pancreatic cancer. Cancer Res. 2012;72: 2481-90.

Yamamoto S, Tomita Y, Hoshida Y, Morooka T, Nagano H, Dono $\mathrm{K}$, et al. Prognostic significance of activated Akt expression in pancreatic ductal adenocarcinoma. Clin Cancer Res. 2004;10:2846-50.

Yeo CJ, Cameron JL. Improving results of pancreaticoduodenectomy for pancreatic cancer. World J Surg. 1999;23:907-12.

Yokoyama S, Higashi M, Kitamoto S, Oeldorf M, Knippschild U, Kornmann M, et al. Aberrant methylation of MUC1 and MUC4 promoters are potential prognostic biomarkers for pancreatic ductal adenocarcinomas. Oncotarget. 2016;7: 42553-65.

Zhang Y, Yang J, Li H, Wu Y, Zhang H, Chen W. Tumor markers CA19-9, CA242 and CEA in the diagnosis of pancreatic cancer: a meta-analysis. Int J Clin Exp Med. 2015;8:1168391.

Zhou L, Lu Z, Yang A, Deng R, Mai C, Sang X, et al. Comparative proteomic analysis of human pancreatic juice: methodological study. Proteomics. 2007;7:1345-55. 